\title{
Luciano Stecca, Montaigne, Plutarco e il poeta Ermodoro/Ermodoto
}

\section{Filippo Fonio}

\section{Q OpenEdition}

1 Journals

\section{Edizione digitale}

URL: https://journals.openedition.org/studifrancesi/37473

DOI: 10.4000/studifrancesi.37473

ISSN: 2421-5856

\section{Editore}

Rosenberg \& Sellier

\section{Edizione cartacea}

Data di pubblicazione: 15 décembre 2004

Paginazione: $597-598$

ISSN: 0039-2944

\section{Notizia bibliografica digitale}

Filippo Fonio, «Luciano Stecca, Montaigne, Plutarco e il poeta Ermodoro/Ermodoto», Studi Francesi [Online], 144 (XLVIII | III) | 2004, online dal 30 novembre 2015, consultato il 08 mai 2021. URL: http:// journals.openedition.org/studifrancesi/37473 ; DOI: https://doi.org/10.4000/studifrancesi.37473

Questo documento è stato generato automaticamente il 8 mai 2021.

\section{(c) (i) (9)}

Studi Francesi è distribuita con Licenza Creative Commons Attribuzione - Non commerciale - Non opere derivate 4.0 Internazionale. 


\title{
Luciano Stecca, Montaigne, Plutarco e il poeta Ermodoro/Ermodoto
}

\author{
Filippo Fonio
}

\section{NOTIZIA}

LUCIANO STECCA, Montaigne, Plutarco e il poeta Ermodoro/Ermodoto, in Lingua, cultura e testo. Miscellanea di studi francesi in onore di Sergio Cigada, a cura di Enrica GALAzZI e Giuseppe BERNARDELLI, vol. II, t. 1, Milano, V \& P Università, 2003, pp. 1197-1209.

1 Il presente studio è finalizzato alla messa in luce dei rapporti intercorrenti fra Montaigne e Plutarco in relazione a un passo dell'Essai I, 42, De l'inequalité qui est entre nous. Si tratta dell'aneddoto del re Antigono e del poeta Ermodoro, del quale si trova traccia in Plutarco, (De Iside et Osiride e Apophthegmata). In Plutarco tuttavia, al cui aneddoto nella forma narrata negli Apophthegmata Montaigne presumibilmente si rifà, il nome del poeta è Ermodoto, come del resto nel Plutarco di Amyot e nelle versioni latine. Negli Apophthegmata di Erasmo e nel Quart Livre di Rabelais, che riprendono l'aneddoto di Antigono prima di Montaigne, il nome del poeta resta pure Ermodoto. Il fatto che la quasi totalità degli editori dell'opera di Montaigne non renda conto dello scarto farebbe propendere per l'ipotesi di una semplice svista priva di rilevanza. Lo studioso ritiene invece che la scelta di Montaigne sia consapevole, o si tratti comunque di una svista non immotivata, e che la ragione di essa sia da ricercarsi nell'orizzonte d'attesa legato ai nomi Ermodoto ed Ermodoro. L'indagine compiuta sulle letture di Montaigne porta a individuare, circa le tracce del poeta Ermodoto, soltanto Plutarco e Stobeo. Diversi sono invece i personaggi di nome Ermodoro di cui si trova notizia in opere che circolavano a quell'epoca. Oltre a un poeta del quale Montaigne conosceva soltanto pochi versi, doveva essergli più noto un altro Ermodoro, uomo politico efesino destinatario di alcune epistole pseudo-eraclitee che si ritiene Montaigne non possedesse, ma del quale avrebbe trovato notizie nelle Tusculanae di Cicerone, in Diogene Laerzio e di nuovo in Stobeo. Costui, concittadino di Eraclito, sarebbe stato espulso da Efeso perché era il migliore fra gli Efesini, dunque inviso a quanti 
desideravano che nessuno spiccasse sugli altri. Strabone e Plinio aggiungono la notizia che questo Ermodoro avrebbe contribuito alla stesura delle leggi delle Dodici Tavole, dato che comproverebbe il valore del personaggio in questione anche per il mondo romano. Sempre in Diogene Laerzio si trova menzione di due filosofi platonici di nome Ermodoro, uno dei quali in particolare, divenuto celebre per la turpe azione di aver raccolto i dialoghi del maestro per poi venderli una volta recatosi in Sicilia (cfr. Cicerone, Epistulae ad Atticum), è ricordato anche da Lipsio. Nell'Icaromenippo di Luciano di Samosata si trova un altro Ermodoro, filosofo epicureo, anch'egli segnalato per la bassa venalità. L'ultimo della serie di omonimi è un architetto ricordato nel ciceroniano De oratore. L'orizzonte di attesa che si sarebbe venuto a creare intorno al nome di Ermodoro è mostrato attraverso esempi tratti da Turnèbe e Naudé. Lo studioso conclude che "pare non irragionevole avanzare l'ipotesi secondo la quale l'orizzonte d'attesa forte che c'era sul nome Ermodoro sia stato determinante anche nel caso di Montaigne, inducendolo a modificare in tal senso il nome originario" (p. 1206), trovando infine un'emendazione a Montaigne presso alcuni suoi traduttori e imitatori italiani a cavallo fra Cinque e Seicento. 